\title{
Development of a standardized methodology for phenotypical characterizations in apple
}

C. Miranda ${ }^{1, a}$, E. Dapena ${ }^{2}$; V. Urbina ${ }^{3}$, S. Pereira-Lorenzo ${ }^{4}$; P. Errea ${ }^{5}$; MA. Moreno ${ }^{6}$, J. Urrestarazu1; M. Fernandez², AM. Ramos-Cabrer4; MB. Diaz-Hernandez4; A. Pina5; LG. Santesteban ${ }^{1}$; MJ. Laquidain ${ }^{1}$; J. Dalmases ${ }^{3}$; MT. Espiau5; G. Reig6; Y. Gogorcena6; J. Ascasibar7, J. B. Royo ${ }^{1}$

1Dpto. Prod Agraria, Universidad Pública de Navarra, Pamplona, Spain; ${ }^{2}$ Servicio Regional de Investigación y Desarrollo de Asturias, Villaviciosa, Spain; 3Departament d'Hortofructicultura, Botánica i Jardinería, Universitat de Lleida, Lleida, Spain; ${ }^{4}$ Dep. Producción Vexetal, Universidad de Santiago de Compostela. Lugo. Spain, 5Unidad de Fruticultura, Centro de Investigación y tecnología Agroalimentaria de Aragón, Zaragoza, Spain, ${ }^{6}$ Dpto. de Pomología, Estación Experimental de Aula Dei (CSIC), Zaragoza, Spain, ${ }^{7}$ Centro de Investigaciones Agrarias de Mabegondo. Xunta de Galicia. Mabegondo-Abegondo. Spain

\section{Abstract}

The description of phenotypic traits in apple cultivars is generally performed using internationally agreed descriptors such as UPOV guidelines, which defines for each trait several states of expression. However, it is not always possible to classify a cultivar unambiguously using those guidelines, because in practice the states are not clearly enough defined or the example varieties are not always available in the collections. This work presents the results of a harmonization project performed by the teams responsible of the main apple germplasm collections in Spain. The objective was to develop a standardized method for the 57 traits included in the TG/14/9 UPOV guidelines for apple characterization, defining their states of expression in a clear and unambiguous way for Spanish germplasm. Phenotypic data collected for more than 1,600 accessions from Spanish collections were used and the method to define each state depended on the type of expression. For quantitative traits the number of states and their limits were defined according to the variability that exists within and between accessions. For qualitative traits, high-resolution images clearly depicting each state were selected. A standardized characterization protocol for the 57 traits of apple germplasm has been provided, enabling to comparing properly the phenotypes of Spanish genetic resources.

Keywords: Malus x domestica, harmonization, quantitative, qualitative, traits

\section{INTRODUCTION}

The description of phenotypic traits in apple cultivars is generally performed using internationally agreed descriptors such as UPOV guidelines, which defines for each trait several states of expression. However, it is not always possible to classify a cultivar unambiguously using those guidelines, because in practice, the states of expression sometimes are not clearly defined, or the reference varieties used to illustrate the different states are not always available in the collections. The Spanish Program of Plant Genetic Resources integrates apple collections including mainly local cultivars from their respective regions. Though some previous studies about the genetic variability of apple genetics resources from Spain have been already performed, the methods, descriptors and markers

a E-mail: carlos.miranda@unavarra.es 
used on each collection were not standardized. Thus, a complete harmonization work was needed in order to evaluate the complete diversity of Malus spp. in Spain. For doing that, the Spanish Government funded the project "Harmonization of the methodology of characterization, assessment of the genetic diversity and definition of the core collection of the apple germplasm conserved in Spanish genebanks". This paper presents the results on the phenotypical descriptor harmonization performed within the Project, made by the teams responsible of the main apple germplasm collections in Spain. The objective was to develop a standardized method for the 57 traits included in the TG/14/9 UPOV guidelines for apple characterization, defining their states of expression in a clear and unambiguous way for Spanish germplasm.

\section{MATERIAL AND METHODS}

\section{Phenotypic data}

Phenotypic data collected for about 1,600 apple accessions preserved in seven Spanish collections, covering most of the Spanish apple growing areas. The collections involved were those located at Public University of Navarre, SERIDA, Centro de Investigaciones Agrarias de Mabegondo, Cabildos (Tenerife, La Palma and Gran Canaria), University of Lleida, Estación Experimental de Aula Dei-CSIC and CITA of Aragon. Characterization data was available for the 57 descriptors compiled in UPOV guideline TG/14/9 (UPOV, 2005).

\section{Standardization of the quantitative traits}

The methodological assumptions in the standardization of the quantitative traits were that the number of the states of expression within a descriptor would be determined according to i) the real expression range observed within each character (RGa) in all accessions and, ii) the variability measured within each accession (within yearly repeats or within years). As a consequence, a wider expression range and lower variability within accessions would result in a greater number of descriptor states.

The discrimination unit (DU), used to define the size of the trait levels, corresponded to the lowest difference between two accessions that allow considering them as belonging to different states of expression and was calculated using the following expressions:

$$
\begin{aligned}
& \mathrm{DU}=\mathrm{Rg}_{\mathrm{pob}}+\mathrm{SD}_{\text {pob }} \\
& \mathrm{RG}_{\mathrm{max}}=\mathrm{RG}_{\mathrm{m}}+\mathrm{SD}_{\mathrm{m}}
\end{aligned}
$$

where $\mathrm{Rg}_{\text {pob }}$ is the mean range for the accessions with $\mathrm{Rg}_{\mathrm{a}}<\mathrm{Rg}_{\text {max }} . \mathrm{SD}_{\text {pob }}$ is the standard deviation of the accessions with $\mathrm{Rg}_{\mathrm{a}}<\mathrm{Rg}_{\max } . \mathrm{Rg}_{\mathrm{a}}$ is the intra-accession range, that is, the difference between the max and min trait values within each accession, $R G_{m}$ is the mean value of $\mathrm{Rg}_{\mathrm{a}}$ in the set of accessions and $\mathrm{SD}_{\mathrm{m}}$ is the standard deviation for $\mathrm{Rg}_{\mathrm{a}}$.

Once the DU was obtained, the number of expression levels for the trait was calculated using the frequency distribution of mean trait values measured on the set of accessions. The central level was centered on the median of the distribution, and the rest of levels placed at increases/decreases of $1 \mathrm{DU}$ respect of central level.

\section{Standardization of the qualitative traits}

The methodological assumptions in the standardization of the qualitative traits were that the assignment to a trait level should be clear and unambiguous, so that the reference varieties should be avoided whenever possible and being replaced with figures or highresolutions photographs.

The expression levels on each qualitative trait were defined taking into account the collective experience of the members of the Project, and previous standardization works 
(Boré and Fleckinger, 1997; Dapena and Blázquez, 2009; Pereira et al., 2002; Royo et al., 2009; Szalatnay, 2006).

\section{RESULTS AND DISCUSSION}

The standardized characterization protocol applied on 20 quantitative traits allowed the definition of new levels for all the traits (Table 1). In most cases, the number of expression levels defined after the harmonization was different to the UPOV reference cultivar-defined ones, in 13 traits we defined more levels than UPOV, generally 1-2 more, and in 4 traits fewer levels could be observed. The greater changes were observed for the Leaf blade: length (UPOV 11), leaf blade: length/width ratio (UPOV 13), Fruit diameter, ratio height/diameter, width of stalk cavity and width of eye basin (UPOV 26, 27, 49 and 51, respectively) in which tree more classes could be defined, and Fruit: size, for which 3 less classes could be defined.

High-resolution characterization sheets were produced for the 37 qualitative traits in UPOV TG/14/9, describing unambiguously the trait levels. In 10 traits the number of expression levels defined after the harmonization was different to the UPOV defined ones (Table 2), generally obtaining a lower number of unambiguous levels, but for 2 traits (UPOV 14, intensity of green color of leaf blade and UPOV 56, time of harvest) more levels could be differentiated, which indicates the usefulness of using wide and diverse databases to define characterization protocols suitable for germplasm collections with old cultivars.

\section{CONCLUSIONS}

A standardized characterization protocol for the 57 traits of apple germplasm has been provided, enabling to compare properly the phenotypes of Spanish genetic resources. We believe that the methodology can significantly reduce the subjectivity of the classifications for all those who perform this kind of work. However, to reach a higher degree of generalization it would be convenient to use a methodology similar to that used in this work, but based on a wider database from as many international collections as possible.

\section{ACKNOWLEDGEMENTS}

This Project has been funded by the Spanish Ministry of Science and Innovation/National Institute for Agricultural and Food Research and Technology (RF201100017-C05-00).

\section{Literature Cited}

Bore, J.M, and Fleckinger, J. (1997). Pommiers à cidre. Variétés de France. Ed. INRA, Paris. 770p.

Dapena E., and Blázquez M.D. (2009). Descripción de las variedades de manzana de la DOP Sidra de Asturias, SERIDA-INIA, Villaviciosa, 69p.

Pereira, S,. Ascasibar-Errasti J., Ramos-Cabrer A.M., and Piñeiro-Andion J. (2002). Colección de cultivares autóctonos gallegos de manzano del Banco de Germoplsma de Mabegondo. Monog. INIA, Madrid, 466p.

Royo J.B., Gonzalez, J, Laquidain M.J., Miranda, C., and Santesteban L.G. (2009) El manzano autóctono de Navarra. Catálogo de las accesiones del Banco de Germoplasma de la UPNA, Pamplona, 636p.

Szalatnay D. (2006). Obst-Deskriptoren NAP - Descripteurs de Fruits PAN. Agroscope Changins Wädenswil ACW and Vereinigung FRUCTUS

UPOV. (2005). Apple (Fruit Varieties) - Guidelines for the conduct of tests for distinctness, uniformity and stability. TG/14/9. International Union for the Protection of New Varieties of Plants, Geneva. 


\section{$\underline{\text { Tables }}$}

Table 1. Number of expression levels in UPOV TG/14/9 and defined after the harmonization for twenty quantitative traits.

\begin{tabular}{|c|c|c|c|}
\hline & \multirow{2}{*}{ UPOV character } & \multicolumn{2}{|c|}{ no of expression levels } \\
\hline & & UPOV & Harmonized \\
\hline 05 & One-year-old shoot: thickness & 4 & 4 \\
\hline 06 & One-year-old shoot: length of internode & 4 & 4 \\
\hline 09 & One-year-old shoot: number of lenticels & 3 & 4 \\
\hline 11 & Leaf blade: length & 4 & 7 \\
\hline 12 & Leaf blade: width & 3 & 5 \\
\hline 13 & Leaf blade: ratio length/width & 3 & 6 \\
\hline 17 & Petiole: length & 3 & 5 \\
\hline 20 & Flower: diameter with petals & 4 & 5 \\
\hline 24 & Fruit: size & 9 & 6 \\
\hline 25 & Fruit: height & 3 & 5 \\
\hline 26 & Fruit: diameter & 3 & 6 \\
\hline 27 & Fruit: ratio heigth/diameter & 5 & 8 \\
\hline 36 & Fruit: relative area of over colour & 5 & 3 \\
\hline 41 & Fruit: area of russet around stalk & 3 & 3 \\
\hline 46 & Fruit: length of stalk & 5 & 4 \\
\hline 47 & Fruit thickness of stalk & 3 & 4 \\
\hline 48 & Fruit: depth of stalk cavity & 3 & 5 \\
\hline 49 & Fruit: Width of stalk cavity & 3 & 6 \\
\hline 50 & Fruit: depth of eye basin & 3 & 5 \\
\hline & Fruit: width of eye basin & 3 & 6 \\
\hline
\end{tabular}

Table 2. Number of expression levels in UPOV TG/14/9 and defined after the harmonization for ten qualitative traits.

\begin{tabular}{llcc}
\hline \multirow{2}{*}{ UPOV character } & \multicolumn{2}{c}{ no of expression levels } \\
\cline { 3 - 4 } & & UPOV & Harmonized \\
\hline 08 & One-year-old shoot: pubescence & 5 & 4 \\
14 & Leaf blade: intensity of green colour & 3 & 4 \\
15 & Leaf blade: incisions of margin & 5 & 4 \\
19 & Flower: predominant colour at balloon stage & 7 & 6 \\
28 & Fruit: general shape & 7 & 5 \\
36 & Fruit: relative area of over colour & 5 & 3 \\
39 & Fruit: pattern of over colour & 7 & 4 \\
52 & Fruit: firmness of flesh & 5 & 3 \\
56 & Time for harvest & 5 & 9 \\
57 & Time of eating maturity & 9 & 5 \\
\hline
\end{tabular}

